\title{
Article \\ Differential Involvement of ACKR3 C-Tail in $\beta$-Arrestin Recruitment, Trafficking and Internalization
}

\author{
Aurélien Zarca ${ }^{1}$, Claudia Perez ${ }^{1,+} \oplus$, Jelle van den Bor ${ }^{1,+} \oplus$, Jan Paul Bebelman ${ }^{1}$, Joyce Heuninck ${ }^{2}$, \\ Rianna J. F. de Jonker ${ }^{1}$, Thierry Durroux ${ }^{2}$, Henry F. Vischer ${ }^{1}{ }^{\circledR}$, Marco Siderius ${ }^{1}$ and Martine J. Smit ${ }^{1, *}$ \\ 1 Amsterdam Institute for Molecular and Life Sciences (AIMMS), Division of Medicinal Chemistry, \\ Faculty of Science, Vrije Universiteit Amsterdam, De Boelelaan 1108, 1081 HZ Amsterdam, The Netherlands; \\ aurelien.zarca@gmail.com (A.Z.); c.v.perezalmeria@vu.nl (C.P.); j.vanden.bor@vu.nl (J.v.d.B.); \\ j.bebelman@vu.nl (J.P.B.); JONriaDE@hotmail.com (R.J.F.d.J.); h.f.vischer@vu.nl (H.F.V.); \\ m.siderius@vu.nl (M.S.) \\ 2 Institut de Génomique Fonctionnelle (IGF), Université de Montpellier, CNRS, INSERM, \\ 34094 Montpellier, France; joyce_heuninck@hotmail.com (J.H.); Thierry.Durroux@igf.cnrs.fr (T.D.) \\ * Correspondence: mj.smit@vu.nl \\ + These authors contributed equally to this paper.
}

check for updates

Citation: Zarca, A.; Perez, C.; van den Bor, J.; Bebelman, J.P.; Heuninck, J.; de Jonker, R.J.F.; Durroux, T.; Vischer, H.F.; Siderius, M.; Smit, M.J. Differential Involvement of ACKR3 C-Tail in $\beta$-Arrestin Recruitment, Trafficking and Internalization. Cells 2021, 10, 618. https://doi.org/ 10.3390/cells10030618

Academic Editor: Graeme Cottrell

Received: 1 February 2021

Accepted: 8 March 2021

Published: 11 March 2021

Publisher's Note: MDPI stays neutral with regard to jurisdictional claims in published maps and institutional affiliations.

Copyright: (C) 2021 by the authors Licensee MDPI, Basel, Switzerland. This article is an open access article distributed under the terms and conditions of the Creative Commons Attribution (CC BY) license (https:// creativecommons.org/licenses/by/ $4.0 /)$.
Abstract: Background: The atypical chemokine receptor 3 (ACKR3) belongs to the superfamily of G protein-coupled receptors (GPCRs). Unlike classical GPCRs, this receptor does not activate G proteins in most cell types but recruits $\beta$-arrestins upon activation. ACKR3 plays an important role in cancer and vascular diseases. As recruitment of $\beta$-arrestins is triggered by phosphorylation of the C-terminal tail of GPCRs, we studied the role of different potential phosphorylation sites within the ACKR3 C-tail to further delineate the molecular mechanism of internalization and trafficking of this GPCR. Methods: We used various bioluminescence and fluorescence resonance energy transferbased sensors and techniques in Human Embryonic Kidney (HEK) 293T cells expressing WT or phosphorylation site mutants of ACKR3 to measure CXCL12-induced recruitment of $\beta$-arrestins and G-protein-coupled receptor kinases (GRKs), receptor internalization and trafficking. Results: Upon CXCL12 stimulation, ACKR3 recruits both $\beta$-arrestin 1 and 2 with equivalent kinetic profiles. We identified interactions with GRK2, 3 and 5, with GRK2 and 3 being important for $\beta$-arrestin recruitment. Upon activation, ACKR3 internalizes and recycles back to the cell membrane. We demonstrate that $\beta$-arrestin recruitment to the receptor is mainly determined by a single cluster of phosphorylated residues on the C-tail of ACKR3, and that residue $\mathrm{T}^{352}$ and in part $\mathrm{S}^{355}$ are important residues for $\beta$-arrestin1 recruitment. Phosphorylation of the $C$-tail appears essential for ligandinduced internalization and important for differential $\beta$-arrestin recruitment. GRK2 and 3 play a key role in receptor internalization. Moreover, ACKR3 can still internalize when $\beta$-arrestin recruitment is impaired or in the absence of $\beta$-arrestins, using alternative internalization pathways. Our data indicate that distinct residues within the C-tail of ACKR3 differentially regulate CXCL12-induced $\beta$-arrestin recruitment, ACKR3 trafficking and internalization.

Keywords: GPCR; ACKR3; chemokine receptor; protein phosphorylation; $\beta$-arrestins; bioluminescence energy transfer (BRET); homogeneous time resolved fluorescence (HTRF); internalization; protein recruitment; GRKs

\section{Introduction}

Atypical chemokine receptors (ACKRs) are part of the superfamily of seven transmembrane receptors known as G-protein-coupled receptors (GPCRs). These receptors have been coined atypical, since, unlike classical GPCRs, they do not signal via G proteins upon activation [1,2]. ACKRs are believed to scavenge their ligands via internalization to modulate the chemokine availability for canonical chemokine receptors, making them 
chemotactic modulators, influencing many processes such as cell migration, immune response and inflammation [3]. Not surprisingly, ACKRs contribute to the progression of cardiovascular diseases and cancer [3-7].

The atypical chemokine receptor 3 (ACKR3, formerly known as CXCR7) is a GPCR sharing endogenous ligands with chemokine receptors CXCR3 (CXCL11) [8] and CXCR4 (CXCL12) [9]. This receptor has been demonstrated to be involved in, for example, brain development [10], cell migration [11], cancer [7] and cardiovascular diseases [12]. Yet, the molecular mechanisms by which ACKR3 contributes to these processes is unclear. Since it does not seem to signal directly via $G$ proteins in most cell types, with the exception of astrocytes [13], the receptor acts as a $\beta$-arrestin biased GPCR [14]. For classical GPCRs, $\beta$-arrestins act as adaptor proteins, facilitating desensitization via internalization into clathrin-coated pits [15]. Some of these receptors display $\beta$-arrestin-independent internalization $[16,17]$. Beside their role as GPCR regulators, $\beta$-arrestins are also involved in downstream signaling, notably via the mitogen activated protein kinase (MAPK) pathway [18]. Since the atypical receptor ACKR3 does not activate $G$ proteins in most cell types, $\beta$-arrestins are thought to play a major role in ACKR3 signaling and functionality $[19,20]$. Yet, recent studies are nuancing those results $[10,21]$. GPCR phosphorylation is a key regulatory mechanism of receptor activity [22]. Given that phosphorylation of the C-terminal tail (C-tail) of GPCRs by various kinases precedes $\beta$-arrestin recruitment to receptors [22,23], the molecular mechanisms by which C-terminal phosphorylation determines ACKR3 downstream events still needs further clarification [10,24,25]. Differential phosphorylation of residues of the receptor's C-tail via different protein kinases, a process referred to as barcoding, can create different outcomes for the agonist-stimulated GPCR and determines the fate of the receptor, via selective protein recruitment, internalization and trafficking $[26,27]$. Some residues of the C-tail of ACKR3 appear as putative phosphorylation sites based on potential consensus sequences recognized by kinases [10], detected by mass-spectrometry [28-31] and some validated by phosphorylation studies and western blot analysis [10].

In this study, we show that upon CXCL12 stimulation, ACKR3 recruits both $\beta$-arrestin 1 and 2 with equivalent kinetic profiles, via G-protein-coupled receptor kinase (GRK) 2 and 3. ACKR3 internalizes and thereafter, recycles back to the cell surface. We demonstrate that $\beta$-arrestin recruitment to the receptor is potentially determined by a single phosphorylation-cluster on the C-tail, and that single residues serve as key phosphorylation sites for $\beta$-arrestin1 recruitment. Although phosphorylation of the C-tail appears essential for ligand-induced internalization and important for $\beta$-arrestin recruitment, agonist-induced internalization of ACKR3 can also occur in the absence of $\beta$-arrestins.

\section{Materials and Methods}

\subsection{Materials}

CXCL12 was obtained from Almac. CMPD101 was obtained from Tocris Bioscience. Hanks' balanced salt solution, Dulbecco's Modified Eagle medium and penicillin/streptomycin were obtained from Gibco. Fetal bovine serum was obtained from Bodinco (Alkmaar, Netherlands). Coelenterazine-h was obtained from Promega (Madison, WI, USA).

\subsection{Cell Culture}

Human Embryonic Kidney (HEK)293T cells (ATCC) and Clustered Regularly Interspaced Short Palindromic Repeats (CRISPR) HEK293 $\beta$-arrestin1 / $\beta$-arrestin2 KO cells [32,33] were grown at $37^{\circ} \mathrm{C}$ and $5 \% \mathrm{CO}_{2}$ in Dulbecco's Modified Eagle medium (Gibco, Waltham, MA, USA) supplemented with $10 \%$ fetal bovine serum (Bodinco), $50 \mathrm{IU} / \mathrm{mL}$ penicillin, and $50 \mathrm{mg} / \mathrm{mL}$ streptomycin (Gibco).

\subsection{Generation of ACKR3 Mutants}

N-terminus HA-tag and alanine substitution of all serine and threonine residues in the C-tail were introduced by DNA synthesis followed by PCR-based site-directed 
mutagenesis. The PCR fragments were cloned using internal BamHI and NotI restriction sites into a $\mathrm{pCDEF}_{3}$ plasmid already containing the RLuc8 gene with an in frame NotI restriction site at the $5^{\prime}$ end. SNAP-tag ACKR3 mutant constructs were generated from a pcDNA $_{3.1}$ SNAP-tag ACKR3 plasmid kindly provided by Thierry Durroux (Montpellier, France) by cloning the promoter, the SNAP-tag and the N-terminus of ACKR3 into the $\mathrm{pcDEF}_{3} \mathrm{HA}_{\text {-tag }} \mathrm{ACKR} 3$ construct using internal MluI and BstXI restriction sites. Following, the mutant $\mathrm{C}$-tails were introduced using internal BstXI and NotI restriction sites from the HA-tag constructs.

\subsection{Bioluminescence Resonance Energy Transfer (BRET)-Based Recruitment Assay}

$0.4 \mu \mathrm{g}$ of $\mathrm{pcDEF}_{3}-\mathrm{hACKR3-RLuc} \mathrm{[19]} \mathrm{or} \mathrm{pcDEF}_{3}-\mathrm{hACKR} 3 \mathrm{mut}-\mathrm{RLuc}$ and $1.6 \mu \mathrm{g}$ of the completing BRET pair ( $\mathrm{pDDEF}_{3}-\beta$-arrestin1-eYFP, $\mathrm{pcDEF}_{3}-\beta$-arrestin2-mVenus [34], pcDEF $_{3}$-GRK2-mVenus, pcDEF 3 -GRK3-mVenus, pcDEF 3 -GRK5-mVenus, pcDEF 3 -GRK6mVenus [35], Rab5a-mVenus, Rab7a-mVenus, Rab11-mVenus, K-Ras-mVenus [36,37]) plasmids were combined to $12 \mu \mathrm{g}$ of PEI in a total volume of $250 \mu \mathrm{L} 150 \mathrm{mM} \mathrm{NaCl}$ and incubated for $20 \mathrm{~min}$ at room temperature. One million resuspended HEK293T or CRISPR HEK293 $\beta$-arrestin1/ $\beta$-arrestin2 KO cells were added to the DNA/PEI mix, and cells were subsequently seeded (30,000 cells per well) in a poly-L-lysine coated (Sigma, Saint-Louis, MO, USA) 96-well white plate (PS, F-bottom, white; Greiner Bio One, Kremsmünster, Austria). Two days after transfection, culture medium was substituted with Hanks' balanced salt solution (Gibco). Next, cells were pre-incubated in Hanks' balanced salt solution for $30 \mathrm{~min}$, in presence or absence of $10 \mu \mathrm{M}$ CMPD101 (Tocris, Bristol, UK) before addition of $2 \mu \mathrm{M}$ Renilla Luciferase substrate coelenterazine-h (Promega). After $10 \mathrm{~min}$, RLuc (480/20 nm) and BRET (540/40 nm) signals were measured on the Mithras LB940 (Berthold Technologies, Bad Wildbad, Germany) or Pherastar FS (BMG Labtech, Ortenberg, Germany) with the BRET1 module (BMG Labtech) and cells were stimulated with $100 \mathrm{nM}$ CXCL12 (Almac, Craigavon, UK) before measuring in real-time. BRET ratios were calculated as: BRET/Rluc signal. Fold vehicle ratio was calculated as: BRET ratio (stimulated)/BRET ratio (vehicle). Data was analyzed using Prism 7 (GraphPad, San Diago, CA, USA).

\subsection{Diffusion-Enhanced Resonance Energy Transfer (DERET)-Based Internalization Assay}

HEK293T cells were transfected in the 96-well plate (Greiner Bio One, PS, F-bottom, white) using lipofectamine2000 (ThermoFisher, Waltham, MA, USA) agent according to manufacturer's protocol. Ninety-six-well plates were coated with poly-ornithine (Sigma). For each well, a total of $200 \mathrm{ng}$ of DNA (2 ng pcDNA $3.1-S N A P-h A C K R 3-R L u c$ combined with $198 \mathrm{ng} \mathrm{pcDEF}_{3}$ plasmid) was diluted in optiMEM (ThermoFisher) to have a total volume of $25 \mu \mathrm{L}$. To this, $0.5 \mu \mathrm{L}$ lipofectamine 2000 mixed with $24.5 \mu \mathrm{L}$ optiMEM was added. The transfection mixture was then incubated for $15 \mathrm{~min}$ at room temperature. Fifty $\mu \mathrm{L}$ of this mix was added to each well and $100 \mu \mathrm{L}$ of medium containing 25,000 HEK293T cells was added on top of the transfection mixture. Two days after transfection, plates were washed twice with $100 \mu \mathrm{L}$ TagLite ${ }^{\circledR}$ buffer (Cisbio, Codolet, France) and incubated with $75 \mu \mathrm{L} 100 \mathrm{nM}$ SNAP-Lumi4-Tb (Cisbio) at $16{ }^{\circ} \mathrm{C}$ to block constitutive internalization for at least $1 \mathrm{~h}$ 30. Plates were then washed four times with $100 \mu \mathrm{L}$ TagLite ${ }^{\circledR}$. Ninety $\mu \mathrm{L} 25 \mu \mathrm{M}$ fluorescein (Cisbio) (diluted in TagLite ${ }^{\circledR}$ ) was added per well and $10 \mu \mathrm{L}$ buffer or CXCL12 solution (ten times concentrated) were added per well. Internalization was followed as a ratio of $620 / 520 \mathrm{~nm}$ while exciting Lumi4-Tb at $340 \mathrm{~nm}$ and measured on the Infinite F500 plate reader (TECAN, Männedorf, Switzerland). 620/520 ratios were normalized to values between 0 and 1. Data was analyzed using Prism 7 (GraphPad).

\subsection{Western Blot}

Western blots were performed as previously published [38]. Briefly, cells were lysed with RIPA buffer (25 mM Tris-HCl (pH 7.4), $150 \mathrm{mM} \mathrm{NaCl}, 0.1 \%$ SDS, 1\% (v/v) NP40, 0.5\% Na-deoxycholate supplemented with $1 \mathrm{mM} \mathrm{NaF}, 1 \mathrm{mM} \mathrm{NaVO} 4$ and cOmplete protease inhibitor cocktail (Roche, Basel, Switzerland), sonicated and centrifuged to remove insoluble 
cell debris. Protein content of the lysates was determined using a bicinchoninic acid assay (BCA) protein estimation assay according to manufacturer's instructions (Thermo Scientific, Waltham, MA, USA). Western blot was performed according to standard procedure and blotted against: $\beta$-arrestin1/2 (\#4674 1:1000 in 5\% milk powder; Cell Signaling, Danvers, MA, USA), $\beta$-actin (A5316 1:1000 in 5\% BSA; Sigma-Aldrich, Saint-Louis, MO, USA). The western blot images were acquired by the use of a ChemiDoc imager (Bio-Rad, Hercules, CA, USA) and quantified by densitometry using Image Lab software (Bio-Rad).

\section{Results}

\subsection{ACKR3 Recruitment of $\beta$-Arrestins}

To study CXCL12-induced $\beta$-arrestin recruitment by ACKR3, we expressed wild type ACKR3 fused with Renilla luciferase (RLuc) on the C-terminal tail (ACKR3-RLuc) as well as $\beta$-arrestin1 tagged with the eYFP fluorescent protein ( $\beta$ arrestin1-eYFP), or $\beta$ arrestin2 tagged with the mVenus fluorescent protein (ßarrestin2-mVenus), creating a Bioluminescent Resonance Energy Transfer (BRET) pair sensor [39] in HEK293T (human embryonic kidney) cells. As previously described [40], ACKR3 recruited $\beta$-arrestin1 and $\beta$-arrestin2 upon CXCL12 stimulation (Figure 1a). The kinetics of recruitment of both $\beta$-arrestins to ACKR3 were similar, with a rapid association phase in the first ten minutes, followed by a slow-increasing plateau phase (Figure 1a). $\mathrm{pEC}_{50}$ values are also similar for the two isoforms (8.1 vs. 8.2) (Figure 1b, Table 1).

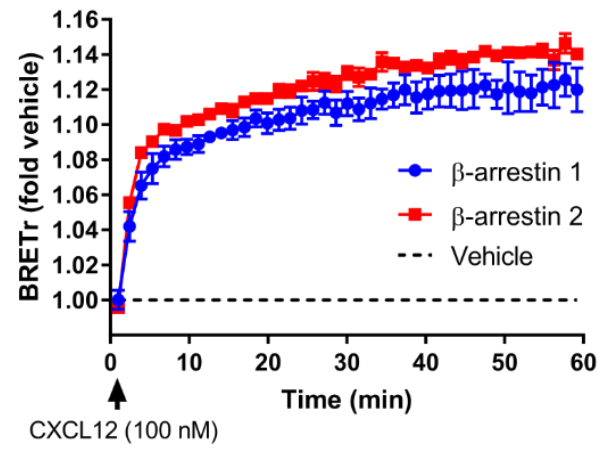

(a)

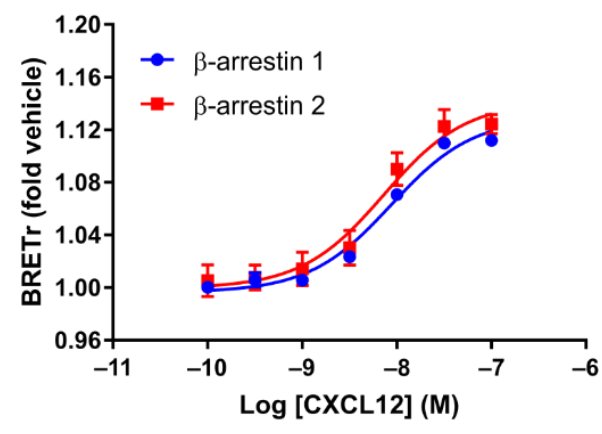

(b)

Figure 1. $\beta$-arrestin1 and $\beta$-arrestin2 recruitment to ACKR3 upon CXCL12 stimulation. (a) CXCL12-induced $\beta$-arrestin1 and $\beta$-arrestin2 recruitment to ACKR3 over time as measured by BRET in ACKR3 WT HEK293T cells; (b) Agonist-induced $\beta$-arrestin1 and $\beta$-arrestin2 recruitment to ACKR3 by increasing concentrations of CXCL12 as measured by BRET in HEK293T cells. Representative curves of three independent experiments with triplicates shown as mean \pm SD.

Table 1. $\mathrm{pEC}_{50}$ of CXCL12 activating ACKR3 in various BRET assays.

\begin{tabular}{cccccccccc}
\hline & & \multicolumn{3}{c}{ BRET Results pEC 50 SEM $(n=3)$} & & \\
GRK2 & GRK3 & GRK5 & GRK6 & $\beta$-Arrestin1 & $\beta$-Arrestin2 & K-Ras & Rab5a & Rab7a & Rab11 \\
\hline $8.2 \pm 0.1$ & $8.1 \pm 0.0$ & $8.3 \pm 0.2$ & ND * & $8.1 \pm 0.1$ & $8.2 \pm 0.0$ & $8.9 \pm 0.1$ & $9.1 \pm 0.1$ & ND $^{*}$ & $9.1 \pm 0.1$ \\
\hline
\end{tabular}

All results are average \pm SEM of three independent experiments. ${ }^{*}$ Not detected.

\subsection{ACKR3 Recruitment of GRKs}

Since recruitment of the $\beta$-arrestins to ACKR3 upon activation is triggered by a change in the phosphorylation pattern of the C-tail of the receptor [23], we investigated whether GRKs, proteins involved in GPCR phosphorylation, play a role in ACKR3 activation [22]. We developed BRET sensors to test this hypothesis by fusing the GRK isoforms (GRK2, GRK3, GRK5 and GRK6) to the mVenus fluorescent protein (GRK-mVenus) [35]. Upon addition of CXCL12, ACKR3 clearly recruited GRK2 and GRK3 (Figure 2a,b). Interestingly, ACKR3 also recruits GRK5, a plasma membrane-bound kinase [41]. On the other hand, ACKR3 does not affect trafficking of GRK6 (see [35] for a positive control of the GRK6 
sensor), another plasma membrane-bound kinase. The $\mathrm{pEC}_{50}$ values for recruitment of each of the GRKs are in a similar range as the $\mathrm{pEC}_{50}$ values for recruitment of the $\beta$-arrestins (Table 1). To explore the involvement of GRKs in the functionality of ACKR3, we decided to test the effect of CMPD101, a known specific inhibitor of GRK2/3 [42]. Inhibition of those GRKs, led to a decrease of $\beta$-arrestin1/2 recruitment to the receptor (Figure 2c,d).

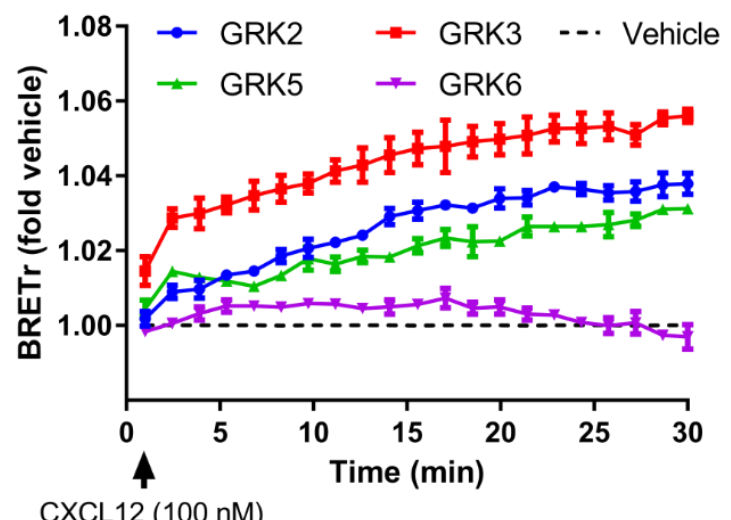

(a)

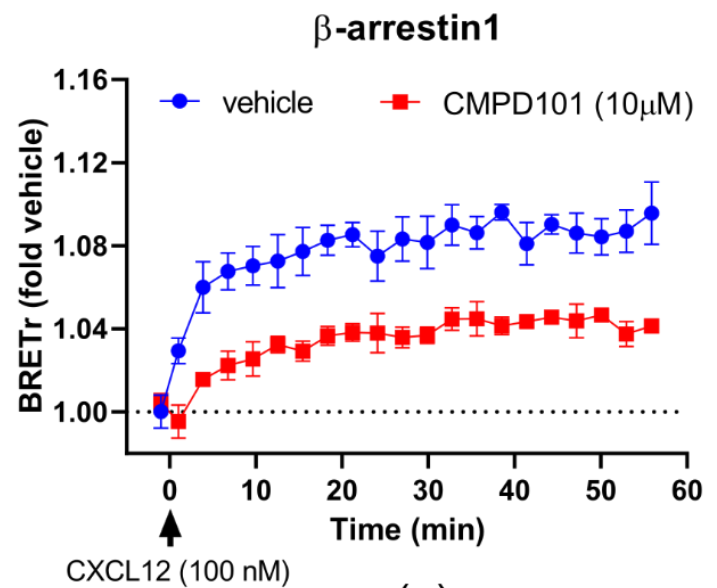

(c)

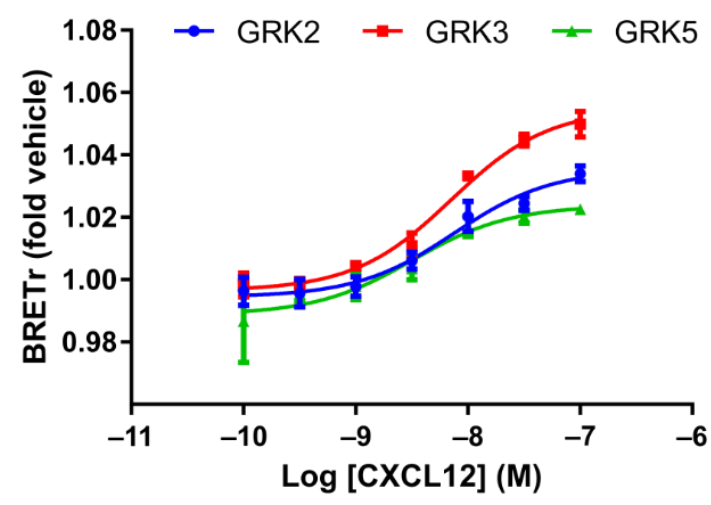

(b)

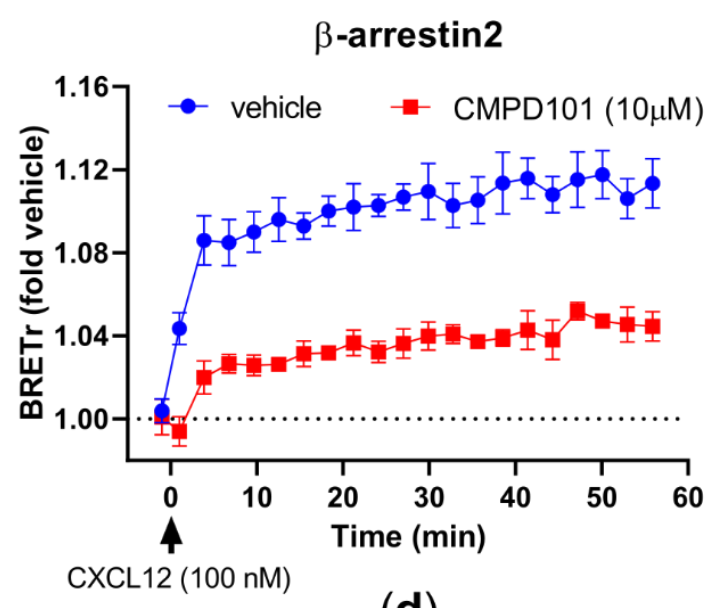

(d)

Figure 2. Influence of GRKs recruitment to ACKR3 upon CXCL12 stimulation. (a) CXCL12-induced GRKs recruitment to ACKR3 over time as measured by BRET in HEK293T cells; (b) Agonist-induced GRKs recruitment to ACKR3 by increasing concentrations of CXCL12 as measured by BRET in HEK293T cells after 30 min stimulation; (c) CXCL12-induced $\beta$-arrestin1 recruitment to ACKR3 over time, in presence or absence of $10 \mu \mathrm{M}$ compound101 as measured by BRET in HEK293T cells; (d) CXCL12-induced $\beta$-arrestin2 recruitment to ACKR3 over time, in presence or absence of $10 \mu \mathrm{M}$ compound101 as measured by BRET in HEK293T cells. Representative curves of three independent experiments with triplicates shown as mean \pm SD.

\subsection{ACKR3 Internalization upon Activation}

Since ACKR3 is considered a decoy or scavenging receptor [14], it is important to monitor trafficking of ACKR3 upon activation by CXCL12. To follow the receptor's fate, we used BRET-based localization sensors [36,37] that are specific for different cell compartments, namely K-Ras (cell membrane) [43], Rab5a (early endosome) [44], Rab7a (late endosome) [45] and Rab11 (recycling endosome) [46]. ACKR3 is known to display constitutive internalization $[19,20,24]$. In this study, we focused on CXCL12-activated internalization of ACKR3 using these cell compartment specific BRET sensors. Upon CXCL12 activation (Figure 3), ACKR3 rapidly disappears from the cell membrane (K-Ras), and relocalizes to early endosome vesicles (Rab5a) (Figure 3a,c). CXCL12 does not seem to trigger degradation of the receptor since it does not co-localize with Rab7a (Figure 3c), a marker of late 
endosomes leading to a degradation pathway for proteins [47]. On the other hand, ACKR3 co-localizes with Rab11 in recycling endosomes, indicating recycling to the cell membrane. Interestingly, $\mathrm{pEC}_{50}$ values linked with internalization (Figure $3 \mathrm{~b}, \mathrm{~d}$ ) are one log unit higher than that of $\beta$-arrestin or GRK recruitment (Figures 1 and 2; Table 1). Pre-treatment of the cells with CMPD101 in the Rab5a and K-Ras BRET assays (Figure 3e,f) showed that the receptor does not translocate to the early endosomes (Figure 3e), and remains at the plasma membrane (Figure 3f), implying impaired internalization. This points to a key involvement of GRK2 and/or GRK3 in the internalization process of ACKR3.

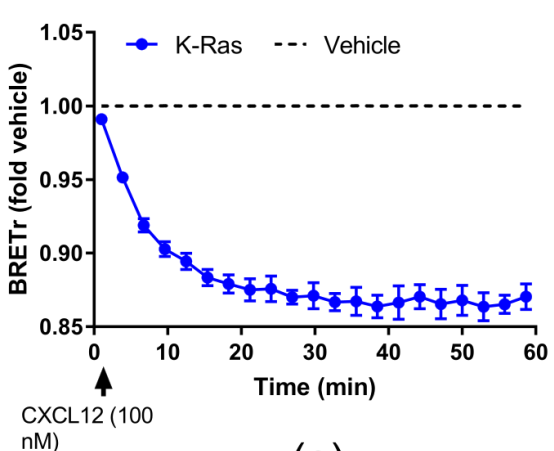

(a)

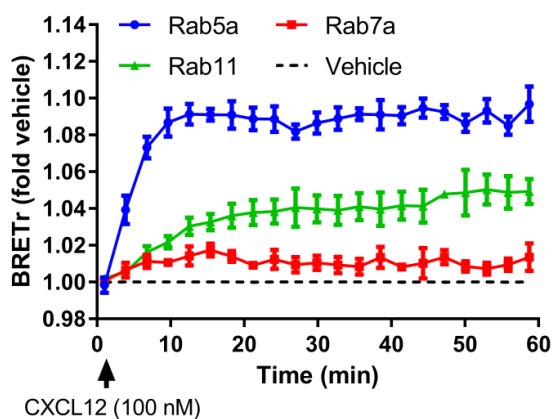

(c)

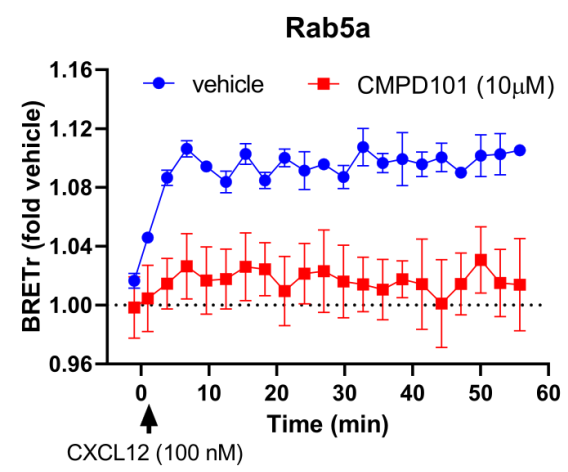

(e)

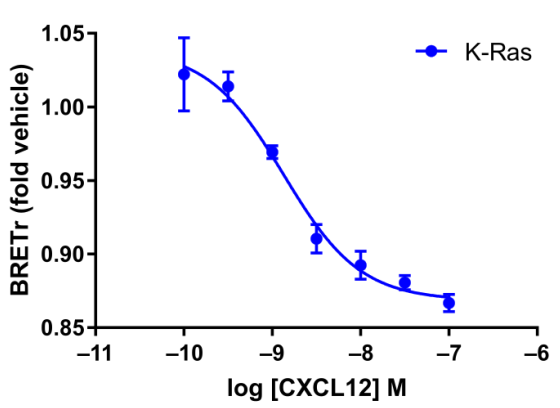

(b)

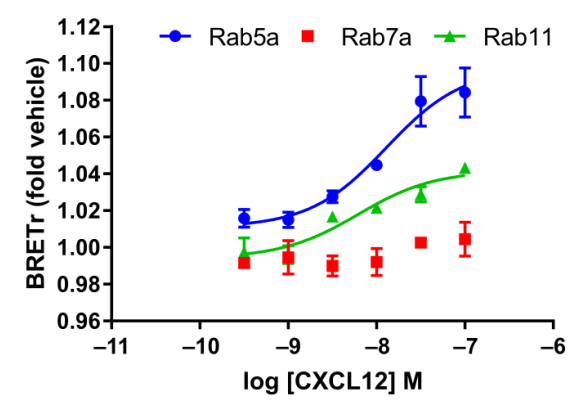

(d)

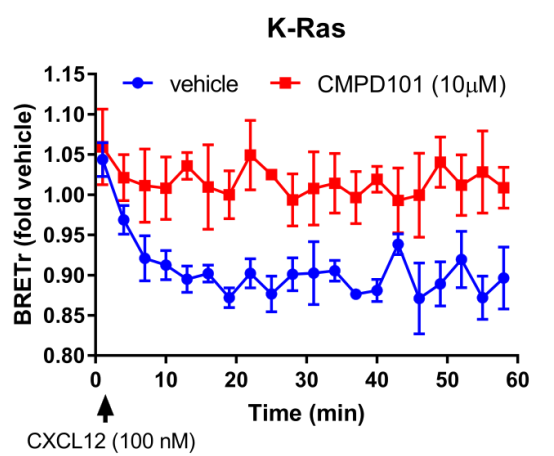

(f)

Figure 3. Internalization, recycling and/or degradation of ACKR3 upon CXCL12 stimulation. (a) CXCL12-induced KRas-Venus co-localization to ACKR3 over time as measured by BRET in HEK293T cells; (b) Agonist-induced K-Ras-Venus co-localization to ACKR3 by increasing concentrations of CXCL12 as measured by BRET in HEK293T cells after 30 min stimulation; (c) CXCL12-induced ACKR3 translocation to indicated Rab-Venus fusion proteins over time as measured by BRET in HEK293T cells; (d) CXCL12-induced ACKR3 translocation to indicated Rab-Venus by increasing concentrations of CXCL12 as measured by BRET in HEK293T cells after 30 min stimulation; (e) CXCL12-induced ACKR3 translocation to Rab5a-Venus over time, in presence or absence of $30 \mu \mathrm{M}$ CMPD101 as measured by BRET in HEK293T cells; (f) CXCL12induced K-Ras-Venus co-localization to ACKR3 over time, in presence or absence of $10 \mu \mathrm{M}$ CMPD101 as measured by BRET in HEK293T cells. Representative curves of three independent experiments with triplicates shown as mean \pm SD. 


\subsection{Involvement C-Tail Phosphorylation Sites ACKR3 in Differential Recruitment of $\beta$-Arrestins}

To investigate the role of phosphorylation of the C-terminus (C-tail) of ACKR3, we generated a set of mutant receptors by mutating potential phosphorylation sites, Serine (S) and Threonine (T) residues, to an Alanine (A) residue. We evaluated these mutants in the BRET-based $\beta$-arrestin recruitment assay. A decrease in BRET signal may indicate a decrease in protein recruitment and/or a decrease in BRET efficiency (donor energy transfer to acceptor) [48], due to changes in orientation of BRET pairs by the alanine substitution. Mutants showing marked effects on $\beta$-arrestin 1 and/or 2 BRET signal were investigated further (Scheme 1). The C-tail consists of two separate clusters of phosphorylation sites and two distal (S360/T361) residues (Scheme 1). When mutating all potential phosphorylation sites of the C-tail (full ST/A), ACKR3 neither recruits $\beta$ arrestin1 nor $\beta$-arrestin2 (Figure $4 \mathrm{a}-\mathrm{c}$ ), suggesting the prerequisite of phosphorylation for CXCL12-mediated $\beta$-arrestin recruitment. Mutating only the two distal residues (ST/A 361-362) of the C-tail did not result in any impairment of $\beta$-arrestin recruitment (Scheme 1, Figure 4a,c). Similarly, combining mutation of cluster 1 and the S360/T361 (ST/A 335-362) did not affect $\beta$-arrestin2 recruitment, but partially impaired the $\beta$-arrestin1 BRET signal (Figure $4 \mathrm{a}, \mathrm{c})$. Cluster 2 contains a GRK2 consensus phosphorylation site [10]. Mutating only $\mathrm{S} / \mathrm{T}$ residues within phosphorylation cluster 2 (S350/T352/S355) in the so-called ST/A 350-355 mutant resulted, like the full ST / A mutant, in a total loss of $\beta$-arrestin recruitment (Figure $4 \mathrm{a}, \mathrm{c}$ ). Finally, by mutating only one residue (T352) within cluster 2 to an alanine (T/A 352), ACKR3 did not recruit $\beta$-arrestin 1 at all, as seen for the full ST/A and ST/A 350-355 mutant (Figure 4a), contrary to S/A 350 (Scheme 1, Figure 4b,d).

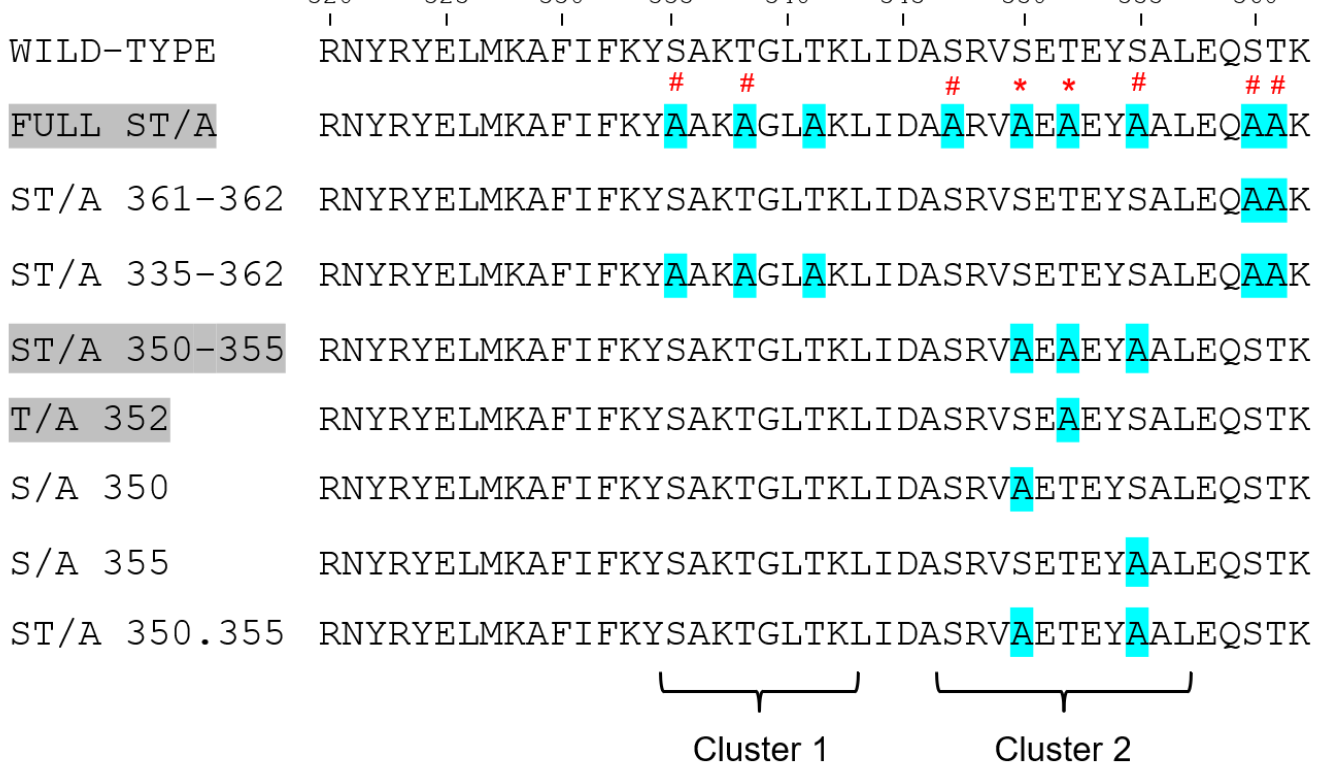

Scheme 1. ACKR3 C-terminal alanine mutants. * Detected and validated phosphorylated residues [10]. \# Detected phosphorylated residues by mass-spectrometry [28-31]. Highlighted mutants were also tested in internalization assays.

The S/A 355 mutant showed impaired $\beta$-arrestin1 BRET signal. Yet, the T/A 352 and S/A 355 mutant were still able to recruit $\beta$-arrestin2 upon binding of CXCL12, with only slightly reduced BRET signal compared to WT ACKR3 for T/A 352 (Figure 4d). The initial kinetic phase of $\beta$-arrestin 2 recruitment is similar, but T/A 352 did not show a continuously increasing plateau phase. These data indicate the differential role of phosphorylation sites in recruitment of $\beta$-arrestin1 and 2. Mutants T/A 352, ST / A 350-355 and full ST/A were deemed most interesting given their varied profiles in $\beta$-arrestin recruitment and therefore characterized further. 


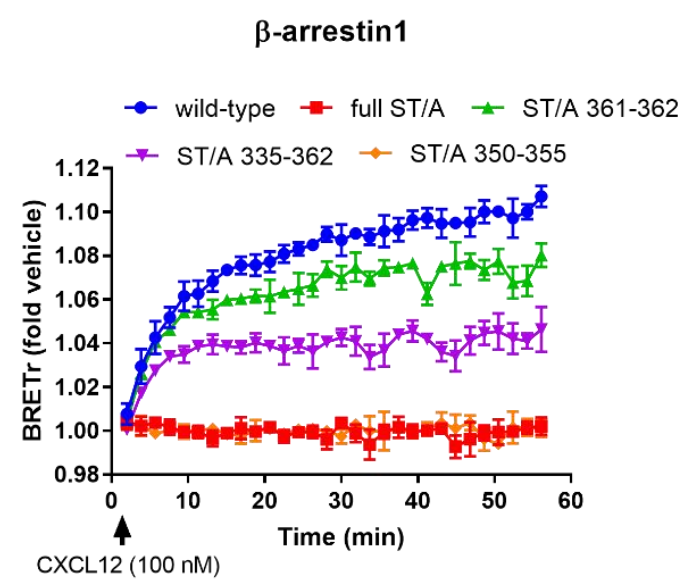

(a)

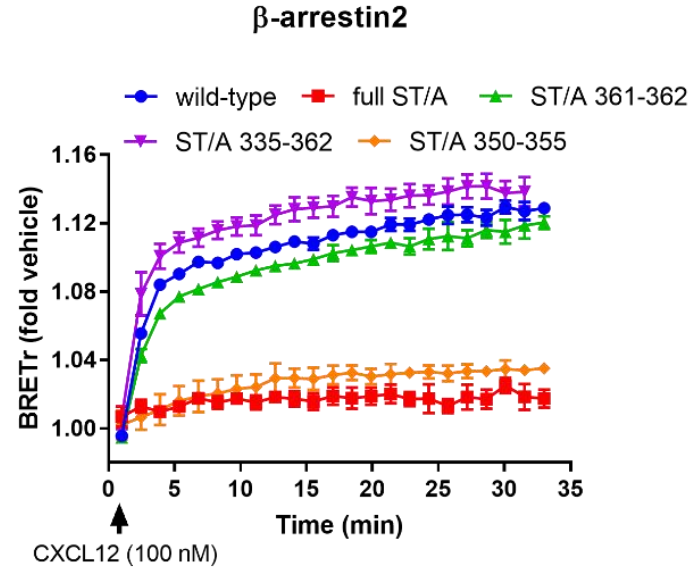

(c)

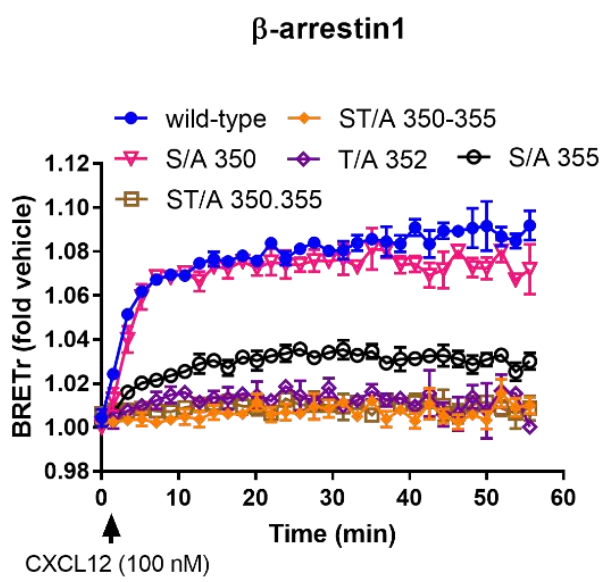

(b)

Figure 4. $\beta$-arrestin1 and $\beta$-arrestin2 recruitment to ACKR3 wild-type and mutant receptors upon CXCL12 stimulation. (a) CXCL12-induced $\beta$-arrestin1 recruitment to ACKR3 wild-type and different cluster mutant receptors over time as measured by BRET in HEK293T cells; (b) CXCL12-induced $\beta$-arrestin1 recruitment to ACKR3 wild-type and cluster 2 mutant receptors over time as measured by BRET in HEK293T cells; (c) CXCL12-induced $\beta$-arrestin2 recruitment to ACKR3 wild-type and different cluster mutant receptors over time as measured by BRET in HEK293T cells; (d) CXCL12induced $\beta$-arrestin 2 recruitment to ACKR3 wild-type and cluster 2 mutant receptors over time as measured by BRET in HEK293T cells. Representative curves of three independent experiments with triplicates shown as mean \pm SD.

\subsection{Involvement C-Tail Phosphorylation Sites ACKR3 in Internalization}

Since phosphorylation of the C-tail of ACKR3 seems to be playing an important role in $\beta$-arrestin recruitment, we studied its effect on CXCL12-mediated ACKR3 internalization. To monitor the internalization of the WT and mutant receptors, we used the BRET-based Rab5a sensor (Figures 3 and 5a), and a TR-FRET (Time-Resolved Fluorescence Resonance Energy Transfer)-based DERET (Diffusion Enhanced Resonance Energy Transfer) approach (Figure 5b) to validate results in an orthogonal assay [49].

To enable the use of this technology with ACKR3, we fused a SNAP tag onto the N-terminus of WT and mutant receptors, to allow labeling by a fluorophore (Lumi4-Tb) and transfected HEK293T with these constructs. Labeling was performed at $16{ }^{\circ} \mathrm{C}$ to prevent protein trafficking in the cells ensuring that Lumi4-Tb will only label receptors initially present at the cell membrane, allowing detection of internalization events when exposing the cells to $37^{\circ} \mathrm{C}$, by a decrease of TR-FRET between the Lumi4-Tb and the non-cell penetrating fluorophore in solution. Upon stimulation by CXCL12 (Figure 5), the internalization kinetics of the WT, the T/A 352 and the ST/A 350-355 mutants are 
similar, albeit with a decrease in internalization rate when comparing ST/A 350/355 with WT. CXCL12 stimulation of the full ST/A mutant only resulted in marginal receptor internalization when using DERET technology (Figure $5 \mathrm{~b}$ ), and no internalization detected using the BRET sensor (Figure 5a). The full ST / A, ST / A 350-355 and T/A 352 ACKR3 mutants showed comparable expression levels in different experimental set ups (Figure S1) not explaining the observed differences. Thus, demonstrating that CXCL12-triggered phosphorylation of the C-tail is necessary for proper internalization of ACKR3, as shown by the removal of all phosphorylation sites.

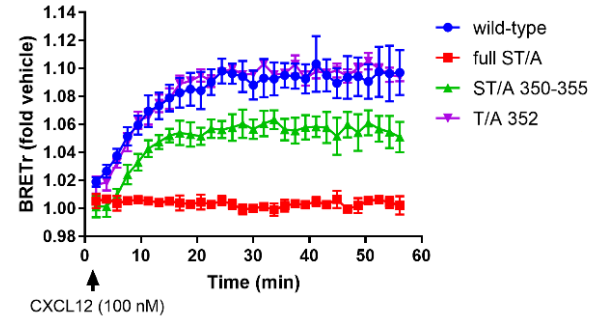

(a)

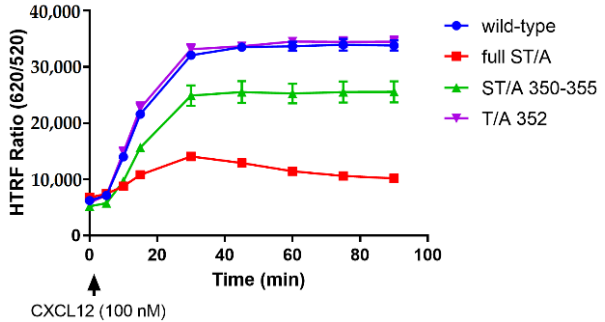

(b)

Figure 5. Agonist-induced internalization of ACKR3 wild-type and mutant receptors. (a) CXCL12-induced ACKR3 wild-type and mutant receptors translocation to Rab5a-Venus ACKR3 over time as measured by BRET in HEK293T cells; (b) CXCL12-mediated internalization of ACKR3 wild-type and mutant receptors over time as measured by TR-FRET in HEK293T cells. Representative curves of at least three independent experiments with triplicates shown as mean \pm SD.

\subsection{Involvement $\beta$-Arrestins in ACKR3 Internalization}

Since mutants defective in $\beta$-arrestin1/2 recruitment still showed internalization, we hypothesized that the internalization process of ACKR3 is not fully dependent on $\beta$-arrestin (Scheme 1, Figure 4a,b and Figure 5), we tested this hypothesis using HEK293T cells in which both $\beta$-arrestin1 and $\beta$-arrestin2 were knocked-out $(\mathrm{KO})$ using CRISPR technology $[32,33]$. Transfecting the K-Ras BRET sensor, a cell membrane-bound protein, along with ACKR3 and the different mutants, we monitored internalization over time of the different receptors. Upon stimulation by CXCL12 (Figure 6), and as previously suggested $[10,21]$, ACKR3 WT does internalize in the absence of $\beta$-arrestins, with similar kinetics as in WT HEK293T (Figure 3). As can be seen in Figure 6, the T/A 352 and ST/A 350-355 mutants are both internalizing in a similar manner as the WT receptor upon activation in the $\beta$-arrestin1/2 CRISPR KO cells. As anticipated from the previous internalization experiments (Figure 5), the lack of phosphorylation sites of the full ST / A mutant prevents it from internalizing when stimulated.

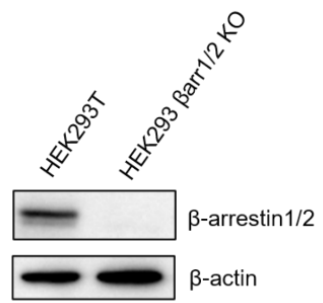

(a)

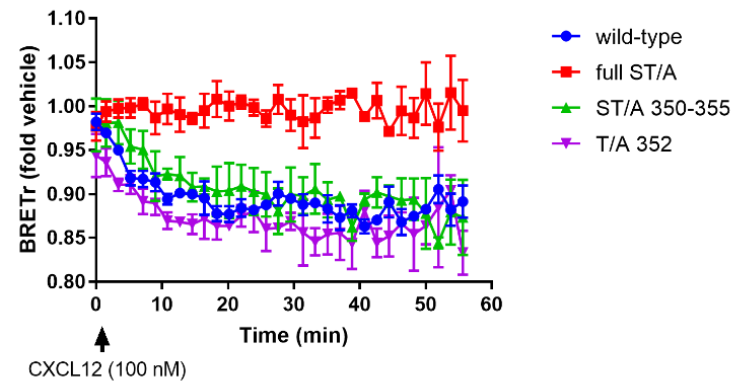

(b)

Figure 6. Internalization of ACKR3 wild-type and mutant receptors in a $\beta$-arrestin1/ $\beta$-arrestin2 KO cell line upon CXCL12 stimulation. (a) Western Blot detection of $\beta$-arrestin1/ $\beta$-arrestin2 expression in HEK293T cells and CRISPR HEK293 $\beta$-arrestin1/ $\beta$-arrestin2 KO cells; (b) CXCL12-induced K-Ras co-localization with ACKR3 wild-type and mutant receptors over time as measured by BRET in CRISPR HEK293 $\beta$-arrestin1/ $\beta$-arrestin 2 KO cells. Representative curves of three independent experiments with triplicates shown as mean $\pm \mathrm{SD}$. 


\section{Discussion}

Accumulating evidence indicates the involvement of ACKR3 in pathological processes, specifically in certain types of cancers and cardiovascular diseases [3,12]. ACKR3, along with CXCR4, with which it shares a ligand, CXCL12 [9], plays an important role in cancer progression $[7,50]$. In this study, we show that, upon CXCL12 stimulation, ACKR3 recruits GRK2 $/ 3 / 5$ proteins and $\beta$-arrestin 1 and 2 with similar kinetics, and internalizes rapidly in endosomal compartments following by its recycling to the membrane. GRK2/3 involvement in ACKR3 phosphorylation is further substantiated by inhibition of CXCL12 mediated $\beta$-arrestin1 and 2 recruitment in the presence of GRK2/3 inhibitor CMPD101. While investigating the impact of phosphorylation of the C-tail on ACKR3 function, we found that phosphorylation is important for recruitment of $\beta$-arrestins, internalization and receptor trafficking. Yet, the $\beta$-arrestins appear dispensable for internalization of ACKR3. The ${ }^{350}$ SETEYS ${ }^{355}$ cluster appears crucial for $\beta$-arrestin 1 and 2 recruitment, with $\mathrm{T}^{352}$ and in part $S^{355}$ serving as key residues for $\beta$-arrestin1 interaction.

Regulation of the ACKR3 lifecycle and signaling remains unclear. In this study, we demonstrate the importance of phosphorylation within the $\mathrm{C}$-tail of the receptor influencing its behavior. The role of $\beta$-arrestins in ACKR3 function is still under debate, with distinct results using different cell types and techniques $[10,19,20,51]$. Here we show equivalent recruitment profiles of both $\beta$-arrestins in HEK293T cells upon overexpression. The sustained $\beta$-arrestin recruitment to the receptor upon CXCL12 activation could be exemplary for the role of ACKR3 sequestering $\beta$-arrestins from CXCR4 [52], thereby modulating indirectly CXCR4 activity.

We show that ACKR3 interacts with GRK2, 3 and 5 upon CXCL12 activation. This is partly in line with the results obtained by Stumm and colleagues [10], demonstrating that GRK2 plays a role in the phosphorylation of the C-tail of ACKR3. Considering that they only investigated the ${ }^{350}{ }^{S E T E}{ }^{353}$ cluster of the C-tail, which is a putative GRK2 phosphorylation consensus site [10], GRK3 and 5 could very well be involved in the phosphorylation of other residues within the C-tail of ACKR3. Interestingly, GRK5 is a plasma membrane-bound kinase [41]. Given that ACKR3 internalizes upon activation (Figure 3), a negative effect on the BRET ratio was expected to appear within a 20 min timeframe with membrane-bound GRK5 separating from the internalizing receptor. Yet, an increase of GRK5 recruitment is observed upon stimulation of ACKR3. Enhanced co-internalization of both ACKR3 and GRK5 in early endosomes could be an explanation for these observations. As recently reported, CMPD101 hampers $\beta$-arrestin2 recruitment via inhibiting GRK2 and 3 activity $[10,53]$. Here, we confirm their data, and furthermore demonstrate that those GRKs are also involved in the recruitment mechanism of $\beta$-arrestin1 and $\beta$-arrestin2. To finetune insight into phospho-barcoding within the ACKR3 C-terminus, involvement of other common GPCR kinases (PKA, PKC) and kinases identified in pulldown experiments of ACKR3 should be investigated as well [13].

As previously published, ACKR3 $[10,19,20,24]$ constitutively internalizes, and we demonstrated it internalizes further upon CXCL12 activation (Figures 3 and 5). BRET experiments of ACKR3 with Rab7a and Rab11 did not reveal agonist-mediated degradation of the receptor but indicated recycling to the plasma membrane. Investigating the role of the C-tail of the receptor and mutating its potentially phosphorylated residues, we generated clear evidence regarding the functional internalization process of the receptor which still occurs in the absence of $\beta$-arrestins. All residues of the ${ }^{350}$ SETEYS ${ }^{355}$ have been detected as being phosphorylated using mass-spectrometry analysis [29], with $S^{350}$ and $\mathrm{T}^{352}$ phosphorylation being validated by western blot [10]. This is in contrast with earlier published data $[19,20]$, but in line with recent experimental work $[10,21]$, showing functional ACKR3 in the absence of $\beta$-arrestins. The differences in cellular background and between full (CRISPR KO approach) or partial inhibition of expression (siRNA approach) may in part explain the observed differences [54]. In this study, we see that agonist-mediated internalization is $\beta$-arrestin1 (T/A 352) and $\beta$-arrestin2 independent (ST / A 350-355). It is possible that $\beta$-arrestins are important for internalization of ACKR3, but in the absence or 
impairment of $\beta$-arrestin1 and 2, alternative internalization pathways may occur resulting in an internalizing receptor. Other GPCRs [16], such as $\mathrm{M}_{2}$ muscarinic receptor, angiotensin $\mathrm{AT}_{1 \mathrm{~A}}$ receptor or formyl peptide receptor can also internalize in a $\beta$-arrestin independent manner. Instead, receptor internalization still occur via clathrin-coated pits $[19,20,24]$, but via other adaptor proteins such as GRK2 [55] or AP-2 [56]. In our study, inhibition of GRK2 and 3 via CMPD101 (Figure 3e,f) showed a marked decrease in internalization of the receptor using Rab5a and K-Ras BRET assays. These data indicate that GRK2, known as an important signaling hub [57], and/or GRK3, are involved in ACKR3 internalization either via their kinase activity or scaffolding role. It will be of interest to further determine the roles of GRK2 and 3, and other kinases or proteins involved in ACKR3 internalization.

Another interesting finding of this study is that $\beta$-arrestin 1 recruitment relies on the potential phosphorylation of $\mathrm{T}^{352}$ and $S^{355}$ residues. Hence, these residues can serve as key phosphorylation sites that direct $\beta$-arrestin 1 interaction and may serve as anchor points to switch on/off the recruitment of $\beta$-arrestin1. Recently, a single phosphorylation residue within the Vasopressin 2 receptor was found to serve as an anchor point for interaction with $\beta$-arrestin 1 and 2 [58]. This key phosphorylation site was suggested to govern the stability of interaction with the $\beta$-arrestins regulating the interdomain rotation in $\beta$-arrestins [58]. Another plausible explanation could be a hierarchical phosphorylation of ACKR3 C-tail, like CXCR4 [59], where phosphorylation of $T^{352}$ and $S^{355}$ would be indispensable for the phosphorylation of further residues directly responsible for $\beta$-arrestin 1 interactions. Here we have identified $\mathrm{T}^{352}$ as a crucial residue for $\beta$-arrestin1 recruitment, with the $S^{355}$ residue having a lesser effect (Figure 4 ) and cluster 1 an even smaller one (Figure 4 ), and $\mathrm{T}^{352}$ only marginally affecting $\beta$-arrestin 2 recruitment. The mutants T/A 352 and S/A 355 represent $\beta$-arrestin 1 deficient mutants that can be used in the future to delineate the contribution of this isoform downstream of ACKR3. Since $\beta$-arrestins are not necessarily involved in internalization of the receptor, studying the impact of differential $\beta$-arrestin recruitment on functional consequences for downstream signaling of ACKR3 is of interest as $\beta$-arrestin functions do not always overlap $[60,61]$, in particular regarding potential MAPK pathway activation [18]. Such studies could be complemented with silencing or knocking-down either $\beta$-arrestin isoform. It is known that $\beta$-arrestins bind in different ways to the receptor, either binding the C-tail, or engaging the core of the GPCR, which can lead to distinct functionality of the GPCR- $\beta$ arrestin complex [62,63].

Phosphorylation of residues within the ${ }^{350}$ SETEYS ${ }^{355}$ (cluster 2) appears crucial for both $\beta$-arrestin 1 and 2 recruitment, and much less for ${ }^{335}{ }^{S A K T G L T}{ }^{341}$ (cluster 1 ) despite having some effect on $\beta$-arrestin1 interactions. There are clear differences of the contribution of phosphorylation sites within cluster 2 , which could lead to differential recruitment of one $\beta$-arrestin isoform over another. It should be noted, however, that there is no evidence thus far of region-specific phosphorylation in different cell types upon agonist exposure. The ST/A 350-355 mutant serves as an ACKR3 $\beta$-arrestin1 and 2-deficient mutant, defective in $\beta$-arrestin1 and 2 recruitment, which may be of interest to dissect the importance of $\beta$-arrestin recruitment for ACKR3 function. Recently, the structure of $\beta$-arrestin2 in complex with the phosphopeptide of the ACKR3 C-tail ${ }^{335}{ }^{\text {SAKTGLT }}{ }^{341}$ (cluster 1) has been resolved [64]. Binding of $\beta$-arrestin 2 was directed by the PxxPxxP motif. It could be imagined that this cluster is responsible for the binding of the arrestins, whether it is phosphorylated or not, while, in accordance with our results, the ${ }^{350}$ SETEYS ${ }^{355}$ cluster is responsible for the differential regulation of the $\beta$-arrestins, and the $C$-tail in its entirety regulating internalization of the receptor. It is also noted that $\beta$-arrestin 2 has been shown to be more flexible than $\beta$-arrestin $1[65,66]$, which may explain why mutation of some of the putative phosphorylation sites have a more pronounced effect on $\beta$-arrestin 1 recruitment.

In summary, we provide evidence of $\beta$-arrestin $1 / 2$ and GRK2/3/5 interactions with ACKR3 upon activation by its cognate ligand CXCL12 (Scheme 2). C-tail phosphorylation of the receptor is a key mechanism for regulation of ACKR3, selectively directing $\beta$-arrestin1 and 2 interactions, and internalization. Agonist-induced internalization of this receptor is GRK2- and/or 3-dependent, yet, in the absence of $\beta$-arrestins, ACKR3 still internalizes. 
Phosphorylation of the distinct sites within the C-tail differentially affects CXCL12-induced $\beta$-arrestin recruitment, and ACKR3 trafficking and internalization. Future studies should further delineate the functional consequences of ACKR3 interacting proteins on its function.
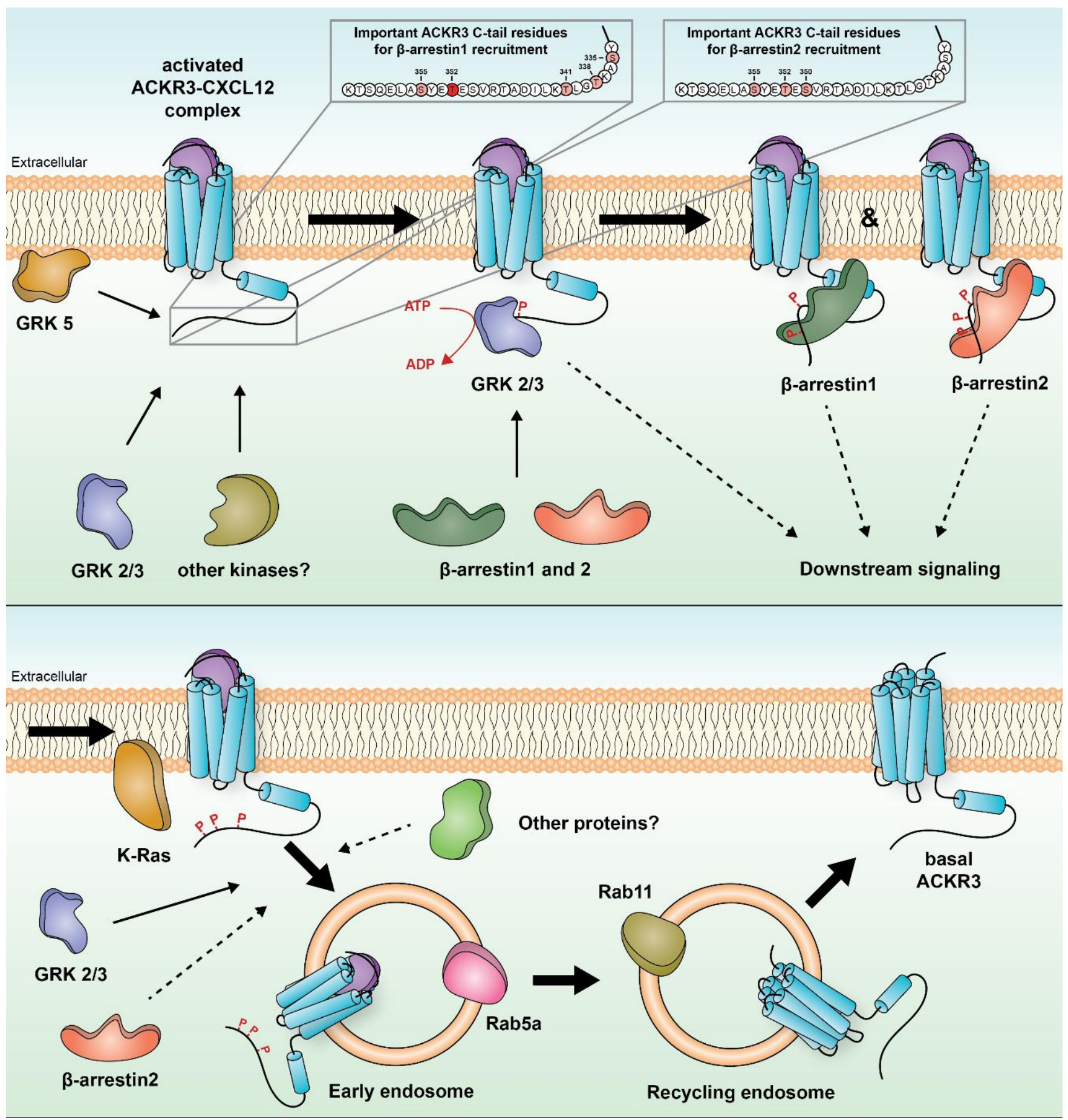

Scheme 2. Proposed model for CXCL12-induced ACKR3 protein recruitment, trafficking and internalization. Upper panel: Upon stimulation via CXCL12, GRK2/3/5, along with potential other kinases, are recruited and phosphorylate the $\mathrm{C}$-tail of the receptor. The phosphorylation of specific residues of the receptor's C-tail is then recognized by $\beta$-arrestin1 and $\beta$-arrestin2, and/or other proteins to trigger downstream signaling. Lower panel: Activation of ACKR3 triggers internalization to the early endosome (Rab5a), via GRK2/3 and $\beta$-arrestin2, and other proteins independently from the canonical $\beta$-arrestins. It is then followed by recycling (Rab11) of the receptor to the cell surface. 
Supplementary Materials: The following are available online at https: / www.mdpi.com/2073-4409/ 10/3/618/s1. Figure S1. Expression levels of ACKR3 wild-type and mutant receptors in various assays.

Author Contributions: Conceptualization, A.Z., H.F.V., M.S., M.J.S.; methodology, A.Z., T.D., H.F.V., M.S., M.J.S.; validation, A.Z., H.F.V., M.S., M.J.S.; formal analysis, A.Z., C.P., J.P.B., J.H., R.J.F.d.J., J.v.d.B.; investigation, A.Z., C.P., J.P.B., J.H., R.J.F.d.J., J.v.d.B.; resources, M.J.S.; data curation, A.Z.; writing-original draft preparation, A.Z.; writing-review and editing, A.Z., J.H., T.D., H.F.V., M.S., M.J.S.; visualization, A.Z.; supervision, H.F.V., M.S., M.J.S.; project administration, M.J.S.; funding acquisition, H.F.V. and M.J.S. All authors have read and agreed to the published version of the manuscript.

Funding: This research was funded by European Union's Horizon2020 Marie Skłodowska-Curie Actions (MSCA) Program under Grant Agreement 641833 (ONCORNET).

Institutional Review Board Statement: Not applicable.

Informed Consent Statement: Not applicable.

Data Availability Statement: The data presented in this study are available in the article and the Supplementary Material.

Acknowledgments: We thank Nevin Lambert from Georgia Health Science University for providing the Rab and K-Ras BRET sensors. We also thank Graeme Milligan from the University of Glasgow and Asuka Inoue from Tohoku University for providing the CRISPR HEK293 $\beta$-arrestin1/ $\beta$-arrestin2 KO cell line. We thank Joyce Koenen as well from INSERM/Université Paris-Saclay for the support.

Conflicts of Interest: The authors declare no conflict of interest.

\section{References}

1. Vacchini, A.; Locati, M.; Borroni, E.M. Overview and potential unifying themes of the atypical chemokine receptor family. J. Leukoc. Biol. 2016, 99, 883-892. [CrossRef] [PubMed]

2. Ulvmar, M.H.; Hub, E.; Rot, A. Atypical chemokine receptors. Exp. Cell Res. 2011, 317, 556-568. [CrossRef] [PubMed]

3. Smit, M.J.; Schlecht-Louf, G.; Neves, M.; van den Bor, J.; Penela, P.; Siderius, M.; Bachelerie, F.; Mayor, F., Jr. The CXCL12/CXCR4/ACKR3 axis in the tumor microenvironment: Signaling, crosstalk, and therapeutic targeting. Annu. Rev. Pharmacol. Toxicol. 2021, 61, 541-563. [CrossRef]

4. Gencer, S.; van der Vorst, E.P.C.; Aslani, M.; Weber, C.; Doring, Y.; Duchene, J. Atypical Chemokine Receptors in Cardiovascular Disease. Thromb. Haemost. 2019, 119, 534-541. [CrossRef]

5. Bonecchi, R.; Graham, G.J. Atypical chemokine receptors and their roles in the resolution of the inflammatory response. Front. Immunol. 2016, 7, 224. [CrossRef]

6. Nibbs, R.J.; Graham, G.J. Immune regulation by atypical chemokine receptors. Nat. Rev. Immunol. 2013, 13, 815-829. [CrossRef]

7. Neves, M.; Fumagalli, A.; van den Bor, J.; Marin, P.; Smit, M.J.; Mayor, F. The role of ACKR3 in breast, lung, and brain cancer. Mol. Pharmacol. 2019, 96, 819-825. [CrossRef]

8. Burns, J.M.; Summers, B.C.; Wang, Y.; Melikian, A.; Berahovich, R.; Miao, Z.; Penfold, M.E.; Sunshine, M.J.; Littman, D.R.; Kuo, C.J.; et al. A novel chemokine receptor for SDF-1 and I-TAC involved in cell survival, cell adhesion, and tumor development. J. Exp. Med. 2006, 203, 2201-2213. [CrossRef] [PubMed]

9. Balabanian, K.; Lagane, B.; Infantino, S.; Chow, K.Y.; Harriague, J.; Moepps, B.; Arenzana-Seisdedos, F.; Thelen, M.; Bachelerie, F. The chemokine SDF-1/CXCL12 binds to and signals through the orphan receptor RDC1 in T lymphocytes. J. Biol. Chem. 2005, 280, 35760-35766. [CrossRef] [PubMed]

10. Saaber, F.; Schutz, D.; Miess, E.; Abe, P.; Desikan, S.; Ashok Kumar, P.; Balk, S.; Huang, K.; Beaulieu, J.M.; Schulz, S.; et al. ACKR3 regulation of neuronal migration requires ACKR3 phosphorylation, but not beta-arrestin. Cell Rep. 2019, 26, 1473-1488.e1479. [CrossRef]

11. Boldajipour, B.; Mahabaleshwar, H.; Kardash, E.; Reichman-Fried, M.; Blaser, H.; Minina, S.; Wilson, D.; Xu, Q.; Raz, E. Control of chemokine-guided cell migration by ligand sequestration. Cell 2008, 132, 463-473. [CrossRef]

12. Wang, C.; Chen, W.; Shen, J. CXCR7 targeting and its major disease relevance. Front. Pharmacol. 2018, 9, 641. [CrossRef]

13. Fumagalli, A.; Heuninck, J.; Pizzoccaro, A.; Moutin, E.; Koenen, J.; Seveno, M.; Durroux, T.; Junier, M.P.; Schlecht-Louf, G.; Bachelerie, F.; et al. The atypical chemokine receptor 3 interacts with Connexin 43 inhibiting astrocytic gap junctional intercellular communication. Nat. Commun. 2020, 11, 4855. [CrossRef]

14. Rajagopal, S.; Kim, J.; Ahn, S.; Craig, S.; Lam, C.M.; Gerard, N.P.; Gerard, C.; Lefkowitz, R.J. Beta-arrestin- but not G proteinmediated signaling by the "decoy" receptor CXCR7. Proc. Natl. Acad. Sci. USA 2010, 107, 628-632. [CrossRef]

15. Tian, X.; Kang, D.S.; Benovic, J.L. beta-arrestins and G protein-coupled receptor trafficking. Handb. Exp. Pharmacol. 2014, 219, 173-186. [CrossRef] [PubMed] 
16. van Koppen, C.J.; Jakobs, K.H. Arrestin-independent internalization of G protein-coupled receptors. Mol. Pharmacol. 2004, 66, 365-367. [CrossRef] [PubMed]

17. Spiess, K.; Bagger, S.O.; Torz, L.J.; Jensen, K.H.R.; Walser, A.L.; Kvam, J.M.; Mogelmose, A.K.; Daugvilaite, V.; Junnila, R.K.; Hjorto, G.M.; et al. Arrestin-independent constitutive endocytosis of GPR125/ADGRA3. Ann. N. Y. Acad. Sci. 2019, 1456, 186-199. [CrossRef] [PubMed]

18. van Gastel, J.; Hendrickx, J.O.; Leysen, H.; Santos-Otte, P.; Luttrell, L.M.; Martin, B.; Maudsley, S. beta-arrestin based receptor signaling paradigms: Potential therapeutic targets for complex age-related disorders. Front. Pharmacol. 2018, 9, 1369. [CrossRef]

19. Canals, M.; Scholten, D.J.; de Munnik, S.; Han, M.K.; Smit, M.J.; Leurs, R. Ubiquitination of CXCR7 controls receptor trafficking. PLoS ONE 2012, 7, e34192. [CrossRef]

20. Luker, K.E.; Steele, J.M.; Mihalko, L.A.; Ray, P.; Luker, G.D. Constitutive and chemokine-dependent internalization and recycling of CXCR7 in breast cancer cells to degrade chemokine ligands. Oncogene 2010, 29, 4599-4610. [CrossRef] [PubMed]

21. Montpas, N.; St-Onge, G.; Nama, N.; Rhainds, D.; Benredjem, B.; Girard, M.; Hickson, G.; Pons, V.; Heveker, N. Ligand-specific conformational transitions and intracellular transport are required for atypical chemokine receptor 3-mediated chemokine scavenging. J. Biol. Chem. 2018, 293, 893-905. [CrossRef]

22. Gurevich, V.V.; Gurevich, E.V. GPCR signaling regulation: The role of GRKs and arrestins. Front. Pharmacol. 2019, 10, 125. [CrossRef] [PubMed]

23. Zhou, X.E.; He, Y.; de Waal, P.W.; Gao, X.; Kang, Y.; Van Eps, N.; Yin, Y.; Pal, K.; Goswami, D.; White, T.A.; et al. Identification of phosphorylation codes for arrestin recruitment by $G$ protein-coupled receptors. Cell 2017, 170, 457-469.e413. [CrossRef]

24. Hoffmann, F.; Muller, W.; Schutz, D.; Penfold, M.E.; Wong, Y.H.; Schulz, S.; Stumm, R. Rapid uptake and degradation of CXCL12 depend on CXCR7 carboxyl-terminal serine/threonine residues. J. Biol. Chem. 2012, 287, 28362-28377. [CrossRef]

25. Fumagalli, A.; Zarca, A.; Neves, M.; Caspar, B.; Hill, S.J.; Mayor, F., Jr.; Smit, M.J.; Marin, P. CXCR4/ACKR3 phosphorylation and recruitment of interacting proteins: Key mechanisms regulating their functional status. Mol. Pharmacol. 2019, 96, 794-808. [CrossRef] [PubMed]

26. Liggett, S.B. Phosphorylation barcoding as a mechanism of directing GPCR signaling. Sci. Signal. 2011, 4, pe36. [CrossRef]

27. Bahouth, S.W.; Nooh, M.M. Barcoding of GPCR trafficking and signaling through the various trafficking roadmaps by compartmentalized signaling networks. Cell Signal. 2017, 36, 42-55. [CrossRef]

28. Klammer, M.; Kaminski, M.; Zedler, A.; Oppermann, F.; Blencke, S.; Marx, S.; Muller, S.; Tebbe, A.; Godl, K.; Schaab, C. Phosphosignature predicts dasatinib response in non-small cell lung cancer. Mol. Cell. Proteom. 2012, 11, 651-668. [CrossRef] [PubMed]

29. Huang, H.; Haar Petersen, M.; Ibanez-Vea, M.; Lassen, P.S.; Larsen, M.R.; Palmisano, G. simultaneous enrichment of cysteinecontaining peptides and phosphopeptides using a cysteine-specific phosphonate adaptable tag (CysPAT) in combination with titanium dioxide $\left(\mathrm{TiO}_{2}\right)$ chromatography. Mol. Cell Proteom. 2016, 15, 3282-3296. [CrossRef]

30. Mertins, P.; Mani, D.R.; Ruggles, K.V.; Gillette, M.A.; Clauser, K.R.; Wang, P.; Wang, X.; Qiao, J.W.; Cao, S.; Petralia, F.; et al. Proteogenomics connects somatic mutations to signalling in breast cancer. Nature 2016, 534, 55-62. [CrossRef]

31. Li, H.; Ren, Z.; Kang, X.; Zhang, L.; Li, X.; Wang, Y.; Xue, T.; Shen, Y.; Liu, Y. Identification of tyrosine-phosphorylated proteins associated with metastasis and functional analysis of FER in human hepatocellular carcinoma cells. BMC Cancer 2009 , 9, 366. [CrossRef]

32. Alvarez-Curto, E.; Inoue, A.; Jenkins, L.; Raihan, S.Z.; Prihandoko, R.; Tobin, A.B.; Milligan, G. Targeted elimination of G proteins and arrestins defines their specific contributions to both intensity and duration of $G$ protein-coupled receptor signaling. J. Biol. Chem. 2016, 291, 27147-27159. [CrossRef]

33. Milligan, G.; Inoue, A. Genome editing provides new insights into receptor-controlled signalling pathways. Trends. Pharmacol. Sci. 2018, 39, 481-493. [CrossRef] [PubMed]

34. Adlere, I.; Sun, S.; Zarca, A.; Roumen, L.; Gozelle, M.; Viciano, C.P.; Caspar, B.; Arimont, M.; Bebelman, J.P.; Briddon, S.J.; et al. Structure-based exploration and pharmacological evaluation of N-substituted piperidin-4-yl-methanamine CXCR4 chemokine receptor antagonists. Eur. J. Med. Chem. 2019, 162, 631-649. [CrossRef] [PubMed]

35. Verweij, E.W.E.; Al Araaj, B.; Prabhata, W.R.; Prihandoko, R.; Nijmeijer, S.; Tobin, A.B.; Leurs, R.; Vischer, H.F. Differential role of serines and threonines in intracellular loop 3 and C-terminal tail of the histamine $\mathrm{H} 4$ receptor in beta-arrestin and $\mathrm{G}$ protein-coupled receptor kinase interaction, internalization, and signaling. ACS Pharmacol. Transl. Sci. 2020, 3, 321-333. [CrossRef]

36. Lan, T.H.; Kuravi, S.; Lambert, N.A. Internalization dissociates beta2-adrenergic receptors. PLoS ONE 2011, 6, e17361. [CrossRef] [PubMed]

37. Lan, T.H.; Liu, Q.; Li, C.; Wu, G.; Lambert, N.A. Sensitive and high resolution localization and tracking of membrane proteins in live cells with BRET. Traffic 2012, 13, 1450-1456. [CrossRef]

38. de Wit, R.H.; Mujic-Delic, A.; van Senten, J.R.; Fraile-Ramos, A.; Siderius, M.; Smit, M.J. Human cytomegalovirus encoded chemokine receptor US28 activates the HIF-1alpha/PKM2 axis in glioblastoma cells. Oncotarget 2016, 7, 67966-67985. [CrossRef]

39. Pfleger, K.D.; Eidne, K.A. Illuminating insights into protein-protein interactions using bioluminescence resonance energy transfer (BRET). Nat. Methods 2006, 3, 165-174. [CrossRef]

40. Luker, K.E.; Gupta, M.; Steele, J.M.; Foerster, B.R.; Luker, G.D. Imaging ligand-dependent activation of CXCR7. Neoplasia 2009, 11, 1022-1035. [CrossRef] 
41. Xu, H.; Jiang, X.; Shen, K.; Fischer, C.C.; Wedegaertner, P.B. The regulator of G protein signaling (RGS) domain of G proteincoupled receptor kinase 5 (GRK5) regulates plasma membrane localization and function. Mol. Biol. Cell. 2014, 25, $2105-2115$. [CrossRef] [PubMed]

42. Thal, D.M.; Yeow, R.Y.; Schoenau, C.; Huber, J.; Tesmer, J.J. Molecular mechanism of selectivity among G protein-coupled receptor kinase 2 inhibitors. Mol. Pharmacol. 2011, 80, 294-303. [CrossRef]

43. Schmick, M.; Vartak, N.; Papke, B.; Kovacevic, M.; Truxius, D.C.; Rossmannek, L.; Bastiaens, P.I.H. KRas localizes to the plasma membrane by spatial cycles of solubilization, trapping and vesicular transport. Cell 2014, 157, 459-471. [CrossRef]

44. Nielsen, E.; Severin, F.; Backer, J.M.; Hyman, A.A.; Zerial, M. Rab5 regulates motility of early endosomes on microtubules. Nat. Cell Biol. 1999, 1, 376-382. [CrossRef]

45. Lebrand, C.; Corti, M.; Goodson, H.; Cosson, P.; Cavalli, V.; Mayran, N.; Faure, J.; Gruenberg, J. Late endosome motility depends on lipids via the small GTPase Rab7. EMBO J. 2002, 21, 1289-1300. [CrossRef] [PubMed]

46. Lock, J.G.; Stow, J.L. Rab11 in recycling endosomes regulates the sorting and basolateral transport of E-cadherin. Mol. Biol. Cell 2005, 16, 1744-1755. [CrossRef]

47. Tjelle, T.E.; Brech, A.; Juvet, L.K.; Griffiths, G.; Berg, T. Isolation and characterization of early endosomes, late endosomes and terminal lysosomes: Their role in protein degradation. J. Cell Sci. 1996, 109, 2905-2914.

48. Brown, N.E.; Blumer, J.B.; Hepler, J.R. Bioluminescence resonance energy transfer to detect protein-protein interactions in live cells. Methods Mol. Biol. 2015, 1278, 457-465. [CrossRef]

49. Levoye, A.; Zwier, J.M.; Jaracz-Ros, A.; Klipfel, L.; Cottet, M.; Maurel, D.; Bdioui, S.; Balabanian, K.; Prezeau, L.; Trinquet, E.; et al. A broad $G$ protein-coupled receptor internalization assay that combines SNAP-Tag labeling, diffusion-enhanced resonance energy transfer, and a highly emissive terbium cryptate. Front. Endocrinol. (Lausanne) 2015, 6, 167. [CrossRef]

50. Sun, X.; Cheng, G.; Hao, M.; Zheng, J.; Zhou, X.; Zhang, J.; Taichman, R.S.; Pienta, K.J.; Wang, J. CXCL12 / CXCR4 / CXCR7 chemokine axis and cancer progression. Cancer Metastasis Rev. 2010, 29, 709-722. [CrossRef] [PubMed]

51. Zabel, B.A.; Wang, Y.; Lewen, S.; Berahovich, R.D.; Penfold, M.E.; Zhang, P.; Powers, J.; Summers, B.C.; Miao, Z.; Zhao, B.; et al. Elucidation of CXCR7-mediated signaling events and inhibition of CXCR4-mediated tumor cell transendothelial migration by CXCR7 ligands. J. Immunol. 2009, 183, 3204-3211. [CrossRef]

52. Coggins, N.L.; Trakimas, D.; Chang, S.L.; Ehrlich, A.; Ray, P.; Luker, K.E.; Linderman, J.J.; Luker, G.D. CXCR7 controls competition for recruitment of beta-arrestin 2 in cells expressing both CXCR4 and CXCR7. PLoS ONE 2014, 9, e98328. [CrossRef] [PubMed]

53. Nguyen, H.T.; Reyes-Alcaraz, A.; Yong, H.J.; Nguyen, L.P.; Park, H.K.; Inoue, A.; Lee, C.S.; Seong, J.Y.; Hwang, J.I. CXCR7: A beta-arrestin-biased receptor that potentiates cell migration and recruits beta-arrestin2 exclusively through Gbetagamma subunits and GRK2. Cell Biosci. 2020, 10, 134. [CrossRef]

54. Luttrell, L.M.; Wang, J.; Plouffe, B.; Smith, J.S.; Yamani, L.; Kaur, S.; Jean-Charles, P.Y.; Gauthier, C.; Lee, M.H.; Pani, B.; et al. Manifold roles of beta-arrestins in GPCR signaling elucidated with siRNA and CRISPR/Cas9. Sci. Signal. 2018, 11. [CrossRef] [PubMed]

55. Shiina, T.; Arai, K.; Tanabe, S.; Yoshida, N.; Haga, T.; Nagao, T.; Kurose, H. Clathrin box in G protein-coupled receptor kinase 2. J. Biol. Chem. 2001, 276, 33019-33026. [CrossRef]

56. Diviani, D.; Lattion, A.L.; Abuin, L.; Staub, O.; Cotecchia, S. The adaptor complex 2 directly interacts with the alpha $1 b$-adrenergic receptor and plays a role in receptor endocytosis. J. Biol. Chem. 2003, 278, 19331-19340. [CrossRef] [PubMed]

57. Penela, P.; Ribas, C.; Sanchez-Madrid, F.; Mayor, F., Jr. G protein-coupled receptor kinase 2 (GRK2) as a multifunctional signaling hub. Cell Mol. Life Sci. 2019, 76, 4423-4446. [CrossRef] [PubMed]

58. Dwivedi-Agnihotri, H.; Chaturvedi, M.; Baidya, M.; Stepniewski, T.M.; Pandey, S.; Maharana, J.; Srivastava, A.; Caengprasath, N.; Hanyaloglu, A.C.; Selent, J.; et al. Distinct phosphorylation sites in a prototypical GPCR differently orchestrate beta-arrestin interaction, trafficking, and signaling. Sci. Adv. 2020, 6. [CrossRef] [PubMed]

59. Mueller, W.; Schutz, D.; Nagel, F.; Schulz, S.; Stumm, R. Hierarchical organization of multi-site phosphorylation at the CXCR4 C terminus. PLoS ONE 2013, 8, e64975. [CrossRef] [PubMed]

60. Gong, K.; Li, Z.; Xu, M.; Du, J.; Lv, Z.; Zhang, Y. A novel protein kinase A-independent, beta-arrestin-1-dependent signaling pathway for $\mathrm{p} 38$ mitogen-activated protein kinase activation by beta2-adrenergic receptors. J. Biol. Chem. 2008, 283, 29028-29036. [CrossRef]

61. Vibhuti, A.; Gupta, K.; Subramanian, H.; Guo, Q.; Ali, H. Distinct and shared roles of beta-arrestin-1 and beta-arrestin-2 on the regulation of C3a receptor signaling in human mast cells. PLOS ONE 2011, 6, e19585. [CrossRef]

62. Shukla, A.K.; Westfield, G.H.; Xiao, K.; Reis, R.I.; Huang, L.Y.; Tripathi-Shukla, P.; Qian, J.; Li, S.; Blanc, A.; Oleskie, A.N.; et al. Visualization of arrestin recruitment by a G-protein-coupled receptor. Nature 2014, 512, 218-222. [CrossRef]

63. Kumari, P.; Srivastava, A.; Ghosh, E.; Ranjan, R.; Dogra, S.; Yadav, P.N.; Shukla, A.K. Core engagement with beta-arrestin is dispensable for agonist-induced vasopressin receptor endocytosis and ERK activation. Mol. Biol. Cell. 2017, 28, 1003-1010. [CrossRef] [PubMed]

64. Min, K.; Yoon, H.J.; Park, J.Y.; Baidya, M.; Dwivedi-Agnihotri, H.; Maharana, J.; Chaturvedi, M.; Chung, K.Y.; Shukla, A.K.; Lee, H.H. Crystal Structure of beta-Arrestin 2 in Complex with CXCR7 Phosphopeptide. Structure 2020, 28, 1014-1023.e1014. [CrossRef] 
65. Zhan, X.; Gimenez, L.E.; Gurevich, V.V.; Spiller, B.W. Crystal structure of arrestin-3 reveals the basis of the difference in receptor binding between two non-visual subtypes. J. Mol. Biol. 2011, 406, 467-478. [CrossRef] [PubMed]

66. Sensoy, O.; Moreira, I.S.; Morra, G. Understanding the differential selectivity of arrestins toward the phosphorylation state of the receptor. ACS Chem. Neurosci. 2016, 7, 1212-1224. [CrossRef] 